\title{
Use of taxane-containing induction chemotherapy in combination with concurrent chemoradiotherapy in Chinese patients with locally advanced nasopharyngeal carcinoma: a meta-analysis
}

\author{
This article was published in the following Dove Press journal: \\ OncoTargets and Therapy \\ 5 November 2015 \\ Number of times this article has been viewed
}

\author{
Rui Tian ${ }^{1, *}$ \\ Hong Xun $\mathrm{Ye}^{2, *}$ \\ Bao Guo Zhang ${ }^{3}$ \\ Dong Ying $\mathrm{Gu}^{3}$ \\ Bing Wen Zhang' \\ Zhi Pan Teng' \\ Mao Yong Jin ${ }^{4}$ \\ Jin Fei Chen ${ }^{3}$ \\ Jian Wei Qi' \\ 'Department of E.N.T., Nanjing First \\ Hospital, Nanjing Medical University, \\ Nanjing, 'Department of Oncology, \\ The People's Hospital of Taixing, \\ Taixing, ${ }^{3}$ Department of Oncology, \\ Nanjing First Hospital, Nanjing \\ Medical University, ${ }^{4}$ Department \\ of Technology, Nanjing Delta \\ Biotechnology Co., Ltd., Nanjing, \\ People's Republic of China \\ *These authors contributed equally \\ to this work
}

Correspondence: Jian Wei Qi Department of E.N.T., Nanjing First Hospital, Nanjing Medical University, 68 Changle Road, Nanjing 210006, People's Republic of China

Tel/fax +862587726234

Email qjw708I8@I63.com

Jin Fei Chen

Department of Oncology, Nanjing First Hospital, Nanjing Medical University, 68 Changle Road, Nanjing 210006 ,

People's Republic of China

Tel/fax +862587726234

Email jinfeichen@sohu.com
Purpose: Taxane-containing induction chemotherapy (IC) regimens in combination with concurrent chemoradiotherapy (CCRT) have been compared with non-taxane-containing IC combined with CCRT in randomized controlled trials (RCTs) in Chinese patients with advanced nasopharyngeal carcinoma (NPC). This meta-analysis aimed to systematically evaluate their clinical efficacy and safety profiling in this ethnic population.

Methods: The electronic databases, PubMed, Embase, MEDLINE, and Chinese Biomedical Database, were searched for eligible studies. The outcomes included overall response rate (ORR), 1-year survival rate, and different types of adverse events. Odds ratios (ORs) and 95\% confidence intervals (CIs) were calculated to evaluate the strength of the associations.

Results: A total of 12 RCTs (representing 835 patients) were identified. The pooled analysis showed that taxane-containing regimens had a significant improvement in ORR for nasopharyngeal lesion $(\mathrm{OR}=4.57,95 \% \mathrm{CI}=1.14-18.30, P=0.032, z=2.15)$ but not in cervical lymph nodes $(\mathrm{OR}=1.23,95 \% \mathrm{CI}=0.65-2.36, P=0.532, z=0.64)$ and in 1 -year survival rates $(\mathrm{OR}=1.19,95 \%$ $\mathrm{CI}=0.10-14.82, P=0.893, z=0.13)$ compared with non-taxane-containing regimens. Regarding the adverse events and toxicities, grade 3-4 leukopenia and neutropenia were significantly different between the two groups $(P<0.001)$ in favor of the non-taxane-containing regimens, but grade 3-4 vomiting was significantly different between the two groups $(P<0.005)$ in favor of the taxane-containing regimens.

Conclusion: When combined with CCRT, taxane-containing IC regimens may be more efficient for short-term local control in Chinese patients with locally advanced NPC than the non-taxane-containing IC regimens. Moreover, the major toxic effects, which were bone marrow suppression, could be tolerated by majority of patients. More long-term follow-up and high-quality trials of NPC are needed to validate our findings.

Keywords: randomized controlled trials, clinical efficacy, safety, survival rate, adverse events, cervical lymph nodes

\section{Introduction}

Nasopharyngeal carcinoma (NPC), a squamous-cell carcinoma, is more prevalent in northern Africa, Alaska, Southeast Asia, and in particular, in the Guangdong area localized at southern part of People's Republic of China, ${ }^{1}$ where its incidence is estimated as 80 cases per 100,000 , which leads to great threat to the health of affected people. ${ }^{2}$ Meanwhile, it is noteworthy that the incidence of NPC is higher among Chinese people immigrated to Southeast Asia or North America but is lower among those born in North America than born in southern part of People's Republic of China. ${ }^{3}$ Obviously, 
there is an urgent need to improve treatment outcomes of NPC patients.

NPC is generally considered to be radio- and chemosensitive in patient care. Several randomized controlled trials (RCTs) have indicated that use of the radiation therapy in combination with chemotherapy synchronously or sequentially is efficient for NPC patients. ${ }^{5,6}$ Currently, concomitant use of radiotherapy and chemotherapy (or called concurrent chemoradiotherapy [CCRT]) is generally recognized as the standard of treatment for locally advanced NPC. ${ }^{7}$ However, clinical observations have shown that $\sim 30 \%-50 \%$ of NPC patients may have metastasis or relapse due to inability to achieve remission, suggesting that current therapy regimen can only control $50 \%-70 \%$ of locally advanced NPC cases successfully. ${ }^{8,9}$ Furthermore, RCTs have demonstrated that CCRT in combination with adjuvant chemotherapy provides a 31\% increase in 3-year overall survival (OS) compared with CCRT alone. ${ }^{10}$ The 2014 National Comprehensive Cancer Network (NCCN) guidelines recommended that CCRT followed by induction chemotherapy (IC) be acceptable for locally advanced NPC (T1N1-3/T2-4Nx). ${ }^{11}$ Despite these advances, standard treatment regimens of IC have not been established as the first-line therapy because any of the following IC regimens could be chosen: docetaxel/cisplatin/ fluorouracil, cisplatin/epirubicin/paclitaxel, and cisplatin/ fluorouracil, the majority of which are taxane-containing regimens.

Taxane is a class of microtubule inhibitors, including paclitaxel and docetaxel (a taxol analog), which works by interfering with cell division. Some evidence has showed that tumor cells would have an increased sensitivity to radiotherapy when patients are treated with docetaxel. ${ }^{12}$ Furthermore, a literature-based meta-analysis indicated the taxane-containing IC regimen (such as combined use of taxane, cisplatin, and fluorouracil) is superior to that not containing taxane (such as combined use of cisplatin and fluorouracil) with respect to progression-free survival and OS in patients with head and neck cancers recruited in randomized trials, ${ }^{13}$ suggesting improved clinical outcomes by taxane. However, there were few discussions on taxane-containing IC regimen in NPC treatment, which compared clinical efficacy and safety of taxane-containing IC plus CCRT with those of non-taxane-containing IC plus CCRT in locally advanced NPC. ${ }^{14-25}$ Here, we aimed to give an overview of all the eligible RCTs for estimated effects of paclitaxel or docetaxel, and to further establish the role of taxane in the standard of IC regimens for locally advanced NPC.

\section{Materials and methods Study design}

To elucidate the inclusion criteria, a protocol was written before literature search. The eligible trials had to meet the following inclusion criteria: the trials should be RCTs, and patients with locally advanced NPC (stage III-IV) should be treated with CCRT in combination with taxane-containing IC or non-taxane-containing IC, without any interference with other treatments. Retrospective studies and prospective studies were used in this meta-analysis.

\section{Literature search}

Electronic databases, such as PubMed, Embase, MEDLINE, and Chinese Biomedical Database, were searched for eligible studies. The search terms included the following keywords: ([nasopharyngeal carcinoma OR nasopharyngeal cancer OR cancer of nasopharynx OR NPC OR NPCa OR nasopharyngeal neoplasms] AND [paclitaxel OR docetaxel OR taxanes OR taxane OR aisui OR dopafei OR taxotere OR taxol] AND [RCTs OR randomized controlled trial]). The language of literature was limited to English and Chinese. In addition, we used the PubMed option "Related Articles" in each paper to retrieve potentially relevant ones, and manually searched the references of all the included articles.

\section{Data extraction}

Two researchers independently performed data extraction (R Tian and BG Zhang) using a standard extraction form. To resolve discrepancies, group consensus and consulting with a third researcher were used (DY Gu). If the eligibility of the abstract was unclear, the full article was retrieved for clarification. Any problems were solved by discussion.

The deadline for trial inclusion was October 14, 2014.

\section{Statistical analysis}

The primary clinical end point was OS, defined as the time from start of randomization until death from any cause. The secondary end points were overall response rate (ORR) and adverse drug reactions.

We used odds ratios (ORs) and $95 \%$ confidence intervals (CIs) to evaluate the strength of the associations. Short-term efficacy, 1-year survival rate, and different types of adverse events were compared with ORs and 95\% CIs using $\chi^{2}$ test. Both the Cochran's $Q$ statistic (testing for heterogeneity) and $I^{2}$ statistic (quantifying the proportion of the total variations due to heterogeneity) were used to estimate heterogeneity across all individual studies included in this meta-analysis. ${ }^{26,27}$ If a $P$-value of the $Q$ test was $<0.05$, indicating a lack of 
heterogeneity across studies, the summary OR estimate of each study was calculated by the fixed-effects model (the Mantel-Haenszel method); ${ }^{28}$ otherwise, random-effects model (the DerSimonian and Laird method) was used. STATA Version 10.0 was used for statistical analysis. All reported $P$-values were two-sided. ${ }^{29}$

\section{Results}

\section{Description of included studies}

Clinical characteristics of recruited NPC patients are summarized in Table 1. The eligible 12 RCTs included one study in English and eleven studies in Chinese, which have been published in the Journals of Statistic Source. ${ }^{14-25}$ A total of 835 patients were enrolled. Among those, 412 (49.3\%) received the taxane-containing $\mathrm{IC}$ regimens, and the rest received non-taxane-containing regimens in addition to CCRT. The sample size ranged from 21 to 76 . All patients were diagnosed with advanced NPC (stage III-IV) histologically or pathologically. All studies were case-control studies, with records of complete remission (CR), partial release (PR), 1-year survival rates, and toxicities.

\section{Short-term efficacy}

Clinical efficacy on primary nasopharyngeal lesion and metastatic lesions of cervical lymph nodes was evaluated for the taxane-containing regimen group and non-taxanecontaining regimen group of NPC patients at 3 months after IC in combination with CCRT. As shown in Table 2, the pooled analysis of the short-term efficacy was performed, in which data on CR and PR of primary nasopharyngeal lesions were assessed in all 12 studies, and metastatic lesions of cervical lymph nodes were evaluated in eight of 12 studies. As shown in Figure 1, taxane-containing IC regimen had a significantly increased ORR for nasopharyngeal lesion (OR $=4.57,95 \% \mathrm{CI}=1.14-18.30, P=0.032, z=2.15)$ but not for cervical lymph nodes $(\mathrm{OR}=1.23,95 \% \mathrm{CI}=0.65-2.36$, $P=0.532, z=0.64)$.

\section{Survival profile}

Survival analyses showed that 1-year survival rate of taxanecontaining IC regimens did not significantly differ from that of non-taxane-containing IC regimens (98.5\% versus $96.2 \%$; $\mathrm{OR}=1.19,95 \% \mathrm{CI}=0.10-14.82, P=0.893, z=0.13)$.

Table I Clinical characteristics of patients with nasopharyngeal carcinoma

\begin{tabular}{|c|c|c|c|c|c|}
\hline Study & Published year & Sample size (n) & Median age (years) & Inclusion period & Therapy regimen \\
\hline \multirow[t]{2}{*}{ Li et al ${ }^{14}$} & 2012 & 35 & $46^{\mathrm{a}}$ & September 2009-March 20II & IC (TPF) + CCRT (ddp + RT) \\
\hline & & 35 & & & IC (PF) + CCRT $(d d p+R T)$ \\
\hline \multirow[t]{2}{*}{ Lu et $\mathrm{al}^{15}$} & 2010 & 29 & 46 & November 2005-November 2008 & IC $(\mathrm{TC})+\mathrm{CCRT}(\mathrm{C}+\mathrm{RT})$ \\
\hline & & 29 & 43 & & IC $(F C)+C C R T(C+R T)$ \\
\hline \multirow[t]{2}{*}{ Han et al ${ }^{16}$} & 2013 & 70 & 42 & January 2005-December 2009 & IC (TP) + CCRT (TP + RT) \\
\hline & & 76 & 45.6 & & IC (NP) + CCRT (NP + RT) \\
\hline \multirow[t]{2}{*}{ Liu et a ${ }^{17}$} & 2013 & 31 & $45^{\mathrm{a}}$ & August 2010-February 2012 & IC (TPF) + CCRT (ddp + RT) \\
\hline & & 32 & & & $\mathrm{IC}(\mathrm{PF})+\mathrm{CCRT}(\mathrm{ddp}+\mathrm{RT})$ \\
\hline \multirow[t]{2}{*}{ Xie et $a^{18}$} & 2007 & 20 & 45 & October 2005-March 2006 & IC (TP) + CCRT (TP + RT) \\
\hline & & 20 & 44 & March 2004-September 2005 & IC $(\mathrm{PF})+\mathrm{CCRT}(\mathrm{PF}+\mathrm{RT})$ \\
\hline \multirow[t]{2}{*}{ Shi et al ${ }^{19}$} & 2013 & 30 & 44 & January 2009-December 2010 & IC (TP) + CCRT (ddp + RT) \\
\hline & & 30 & 46 & & $\mathrm{IC}(\mathrm{PF})+\mathrm{CCRT}(\mathrm{ddp}+\mathrm{RT})$ \\
\hline \multirow[t]{2}{*}{ Ma et $\mathrm{a}^{20}$} & 2011 & 21 & $45^{\mathrm{a}}$ & December 2009-March 201I & IC (TPF) + CCRT (ddp + RT) \\
\hline & & 24 & & & $\mathrm{IC}(\mathrm{PF})+\mathrm{CCRT}(\mathrm{ddp}+\mathrm{RT})$ \\
\hline \multirow[t]{2}{*}{ Luo et $\mathrm{a}^{21}$} & 2011 & 32 & 52 & March 2006-February 2009 & IC $(\mathrm{DN})+\mathrm{CCRT}(\mathrm{N}+\mathrm{RT})$ \\
\hline & & 32 & 54 & & $\mathrm{IC}(\mathrm{PF})+\mathrm{CCRT}(\mathrm{N}+\mathrm{RT})$ \\
\hline \multirow[t]{2}{*}{ Wu et $\mathrm{al}^{22}$} & 2013 & 32 & $45^{\mathrm{a}}$ & January 2010-December 2010 & $\mathrm{IC}(\mathrm{DN})+\mathrm{CCRT}(\mathrm{N}+\mathrm{RT})$ \\
\hline & & 30 & & & IC (PF) + CCRT (N + RT) \\
\hline \multirow[t]{2}{*}{ Huang et $\mathrm{a}^{23}$} & 2013 & 40 & $45^{\mathrm{a}}$ & January 2010-June 2010 & $\mathrm{IC}(\mathrm{TP})+\mathrm{CCRT}(\mathrm{ddp}+\mathrm{RT})$ \\
\hline & & 40 & & & $\mathrm{IC}(\mathrm{PF})+\mathrm{CCRT}(\mathrm{ddp}+\mathrm{RT})$ \\
\hline \multirow[t]{2}{*}{ Ma et $\mathrm{al}^{24}$} & 2009 & 49 & $48^{\mathrm{a}}$ & May 2003-August 2006 & IC (TPF) + CCRT (PF + RT) \\
\hline & & 49 & & & $\mathrm{IC}(\mathrm{PF})+\mathrm{CCRT}(\mathrm{PF}+\mathrm{RT})$ \\
\hline \multirow[t]{2}{*}{ Wu et $a^{25}$} & 2014 & 23 & 44 & N/A & IC (TPF) + CCRT $(d d p+R T)$ \\
\hline & & 26 & 43 & & $\mathrm{IC}(\mathrm{PF})+\mathrm{CCRT}(\mathrm{ddp}+\mathrm{RT})$ \\
\hline
\end{tabular}

Notes: ${ }^{a}$ Only the average of all patients was provided. N/A, information was not available.

Abbreviations: IC, induction chemotherapy; TPF, docetaxel + cisplatin + 5-fluorouracil; CCRT, concurrent chemoradiotherapy; ddp, cisplatin; RT, radiotherapy; PF, cisplatin + 5-fluorouracil; TC, docetaxel + carboplatin; FC, carboplatin + 5-fluorouracil; TP, docetaxel + cisplatin; NP, vinorelbine + cisplatin; DN, docetaxel + nedaplatin; C, carboplatin; $\mathrm{N}$, nedaplatin. 
Table 2 The short-term efficacy in two groups of the included studies

\begin{tabular}{|c|c|c|c|c|c|}
\hline Study & Sample size & CRI & PRI & CR2 & PR2 \\
\hline \multirow[t]{2}{*}{ Li et al ${ }^{14}$} & 35 & 31 & 4 & $\mathrm{~N} / \mathrm{A}$ & $\overline{N / A}$ \\
\hline & 35 & 22 & 12 & $\mathrm{~N} / \mathrm{A}$ & $\mathrm{N} / \mathrm{A}$ \\
\hline \multirow[t]{2}{*}{ Lu et $\mathrm{al}^{15}$} & 29 & 28 & 1 & 24 & I \\
\hline & 29 & 28 & I & 21 & 2 \\
\hline \multirow[t]{2}{*}{ Han et $\mathrm{al}^{16}$} & 70 & 64 & 6 & 60 & 5 \\
\hline & 76 & 72 & 4 & 65 & 6 \\
\hline \multirow{2}{*}{ Liu et $\mathrm{al}^{17}$} & 31 & 26 & 5 & N/A & $\mathrm{N} / \mathrm{A}$ \\
\hline & 32 & 23 & 9 & $\mathrm{~N} / \mathrm{A}$ & $\mathrm{N} / \mathrm{A}$ \\
\hline \multirow[t]{2}{*}{ Xie et $\mathrm{al}^{18}$} & 20 & 20 & 0 & 19 & 1 \\
\hline & 20 & 18 & 2 & 15 & 3 \\
\hline \multirow[t]{2}{*}{ Shi et a $\left.\right|^{19}$} & 30 & 25 & 5 & $\mathrm{~N} / \mathrm{A}$ & $\mathrm{N} / \mathrm{A}$ \\
\hline & 30 & 19 & 9 & $\mathrm{~N} / \mathrm{A}$ & $\mathrm{N} / \mathrm{A}$ \\
\hline \multirow[t]{2}{*}{ Ma et $\mathrm{a}^{20}$} & 21 & 18 & 3 & N/A & $\mathrm{N} / \mathrm{A}$ \\
\hline & 24 & 13 & 10 & N/A & $\mathrm{N} / \mathrm{A}$ \\
\hline \multirow[t]{2}{*}{ Luo et $\mathrm{al}^{21}$} & 32 & 31 & $\mathrm{I}$ & 26 & 2 \\
\hline & 32 & 30 & 2 & 25 & I \\
\hline \multirow[t]{2}{*}{ Wu et $\mathrm{al}^{22}$} & 32 & 29 & 3 & 28 & 4 \\
\hline & 30 & 26 & 4 & 25 & 5 \\
\hline \multirow[t]{2}{*}{ Huang et $\mathrm{al}^{23}$} & 40 & 38 & 2 & 36 & 4 \\
\hline & 40 & 36 & 3 & 37 & 3 \\
\hline \multirow[t]{2}{*}{ Ma et $\mathrm{a}^{24}$} & 49 & 48 & I & 37 & 6 \\
\hline & 49 & 45 & 4 & 36 & 8 \\
\hline \multirow[t]{2}{*}{ Wu et $\mathrm{al}^{25}$} & 23 & 19 & 3 & N/A & N/A \\
\hline & 26 & 18 & 4 & $\mathrm{~N} / \mathrm{A}$ & $\mathrm{N} / \mathrm{A}$ \\
\hline
\end{tabular}

Notes: Data are expressed as n. N/A, information was not available.

Abbreviations: CRI, complete remission of primary nasopharyngeal lesion; PRI, partial release of primary nasopharyngeal lesion; $C R 2$, complete remission of cervical lymph nodes; PR2, partial release of cervical lymph nodes.

\section{Hematological adverse events}

The incidences of adverse events are summarized in Table 3. The occurrence rates of grade 3 and higher leukopenia were $46.7 \%$ and $22.4 \%$, and those of grade 3-4 neutropenia were $39.1 \%$ and $16.1 \%$ in testing group and control group, respectively. As shown in Figures 2 and 3, patients treated with taxane-containing IC regimens in combination with CCRT had a significantly high incidence of grade 3-4 leukopenia $(\mathrm{OR}=3.21,95 \% \mathrm{CI}=2.14-4.83, P<0.001$, $z=5.63)-$ and neutropenia $(\mathrm{OR}=3.62,95 \% \mathrm{CI}=2.42-5.40$, $P<0.001, z=6.29)$ compared to those treated with nontaxane-containing IC regimens. Meanwhile, there were no significant differences in the occurrence rate of other hematological adverse events, such as anemia (OR $=1.46$, $95 \% \mathrm{CI}=0.81-2.63, P=0.214, z=1.24)$ and thrombocytopenia $(\mathrm{OR}=1.67,95 \% \mathrm{CI}=0.99-2.83, P=0.055, z=0.92)$ between these two groups.

\section{Non-hematological adverse events}

Grade 3-4 vomiting $(\mathrm{OR}=0.67,95 \% \mathrm{CI}=0.45-0.99, P=0.043$, $z=2.03$ ) was observed significantly different between the two groups in favor of the taxane-containing group (Figure 4). There were similar incidences of other non-hematological toxicities between the two groups of patients receiving CCRT with or without the taxane-containing IC regimen, such as alanine aminotransferase elevation $(\mathrm{OR}=1.45,95 \%$ $\mathrm{CI}=0.70-2.98, P=0.315, z=0.78)$, oral mucositis $(\mathrm{OR}=1.27$, $95 \% \mathrm{CI}=0.89-1.82, P=0.182, z=0.74)$, dermatitis $(\mathrm{OR}=0.98$, 95\% CI $=0.49-1.99, P=0.963, z=0.05)$, and dry mouth (OR $=0.96,95 \% \mathrm{CI}=0.33-2.81, P=0.941, z=0.09$ ).

\section{Risk of bias assessment}

Data on the incidence of vomiting indicated a lack of heterogeneity across studies ( $P=0.013)$; thus, the random-effects

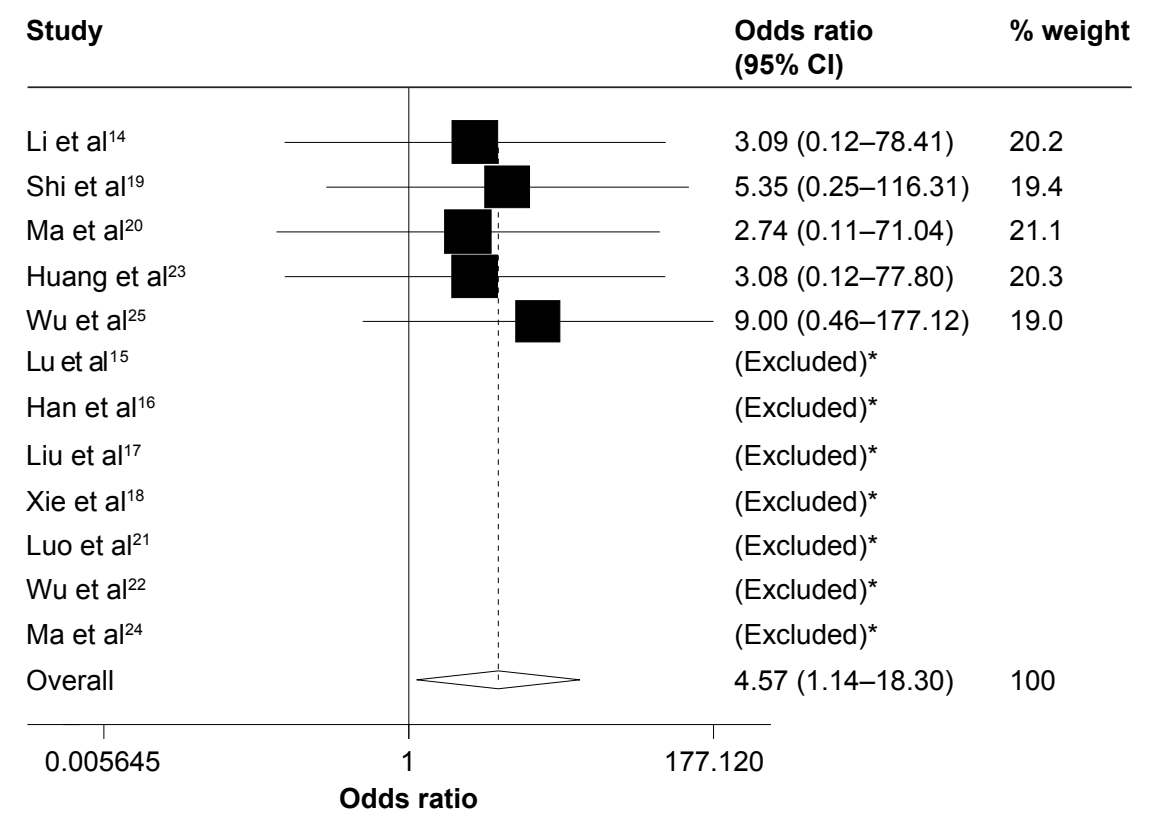

Figure I Forest plot of the overall response rate for asopharyngeal lesion.

Note: *The term '(Excluded)' represents that odds ratio could not be calculated.

Abbreviation: $\mathrm{Cl}$, confidence interval. 


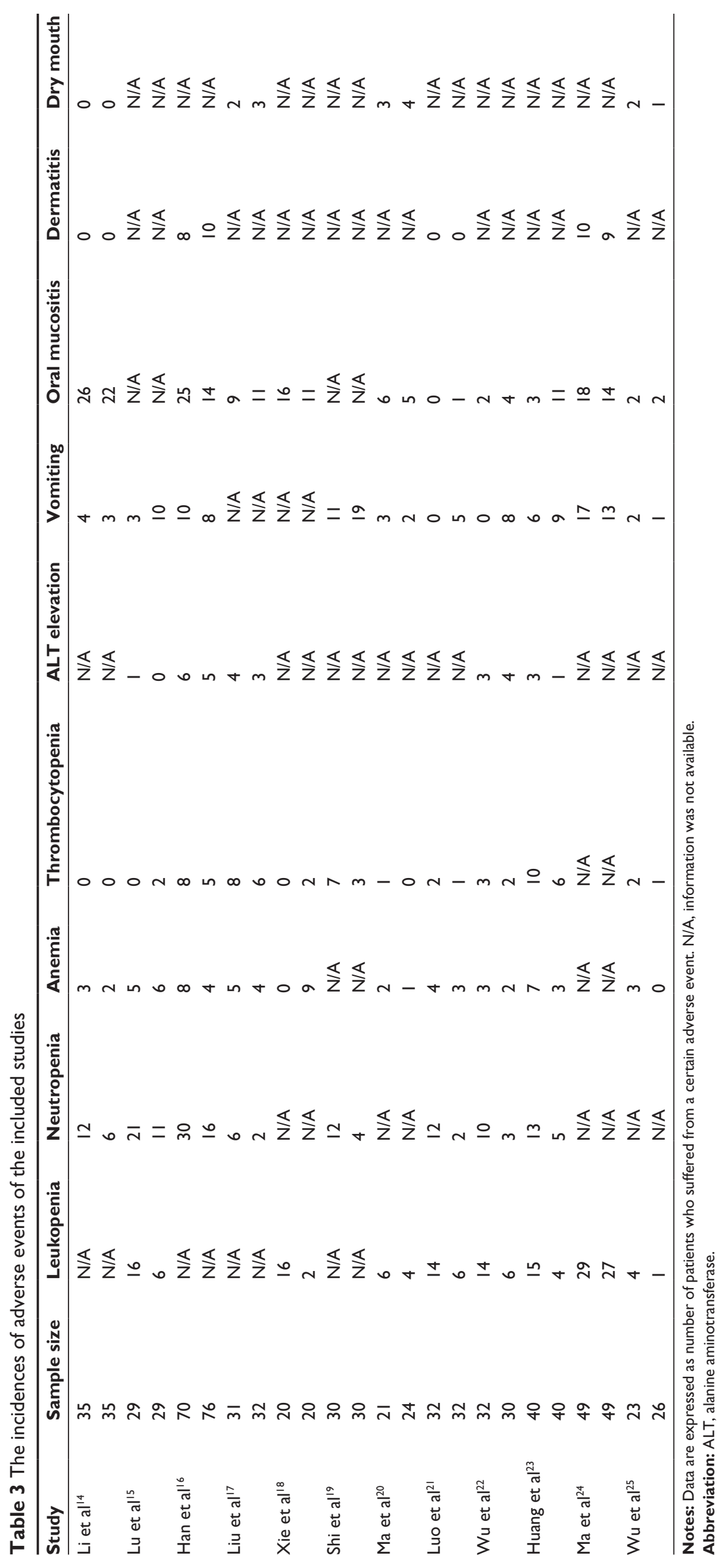




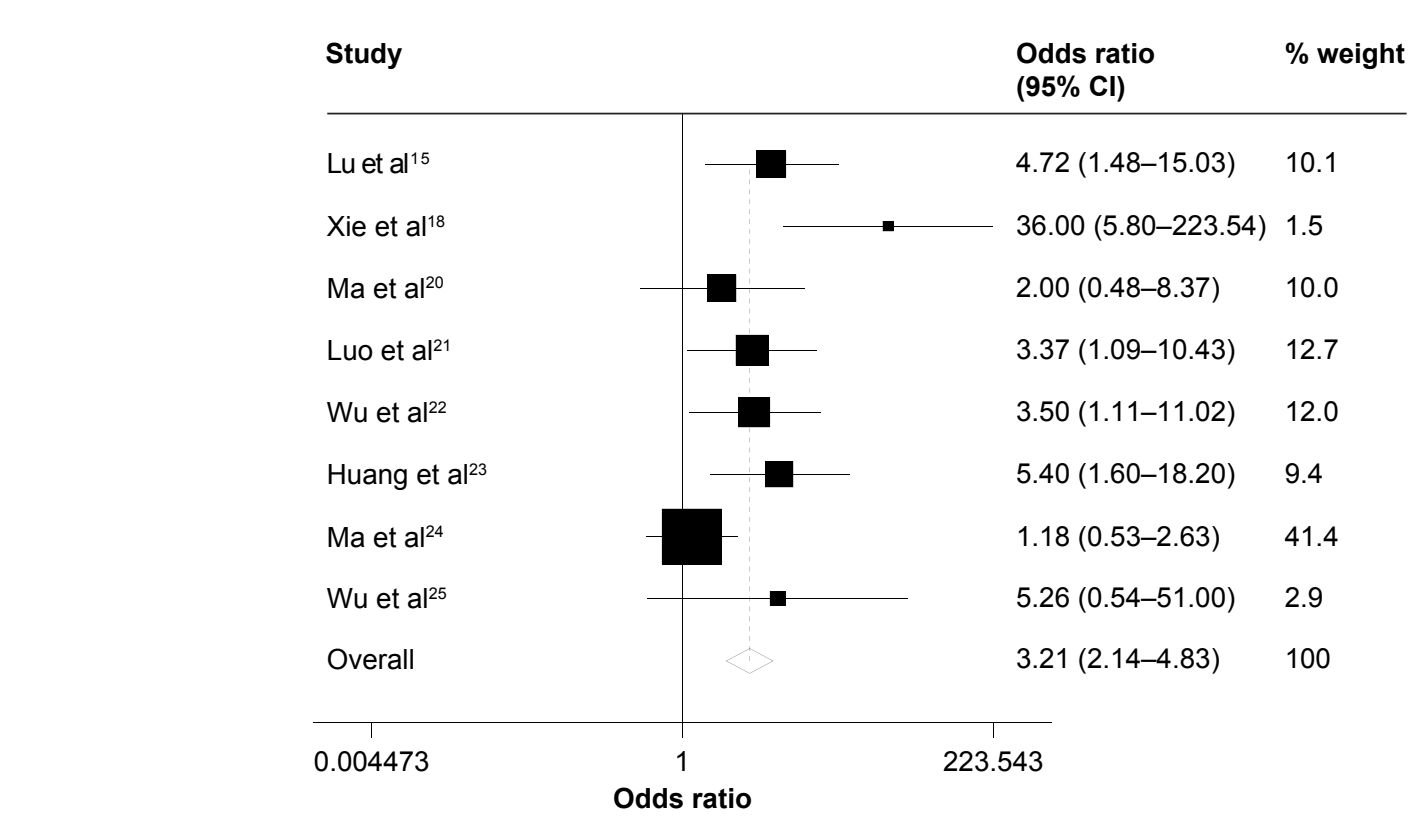

Figure 2 Forest plot of the rate of grade 3-4 leukopenia.

Abbreviation: $\mathrm{Cl}$, confidence interval.

model was used. The fixed-effects model was used in the incidence of other adverse events, short-term efficacy, and 1-year OS.

\section{Discussion}

This study is the first RCT-based meta-analysis that evaluated clinical efficacy and safety of taxane-containing versus non-taxane-containing IC regimens in combination with
CCRT regimen for locally advanced NPC in Chinese people, revealing remarkably improved ORR for nasopharyngeal lesion. In addition, the two IC regimens were well tolerated by all patients, although grade 3-4 vomiting was observed to be significantly different between the two groups in favor of the taxane-containing regimen, and grade 3-4 leukopenia and neutropenia were significantly different in favor of the non-taxane-containing regimen.

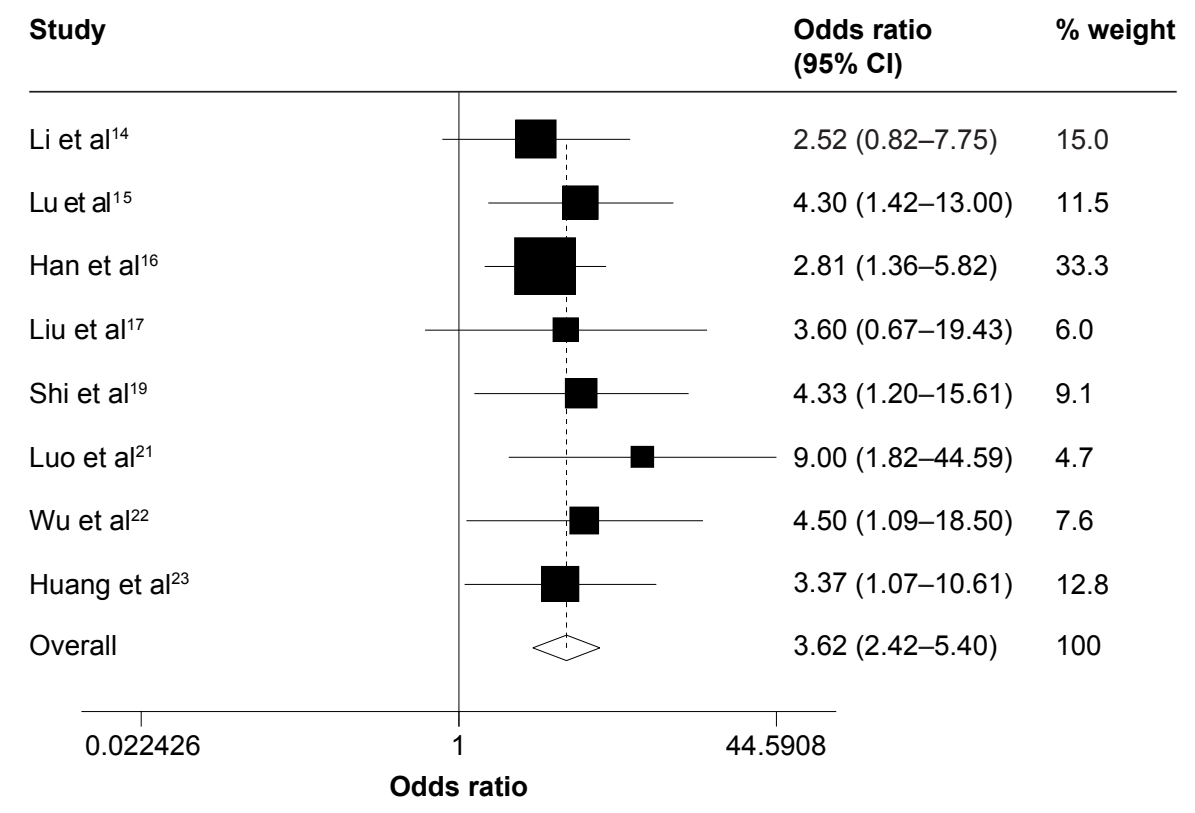

Figure 3 Forest plot of the rate of grade 3-4 neutropenia. Abbreviation: $\mathrm{Cl}$, confidence interval. 


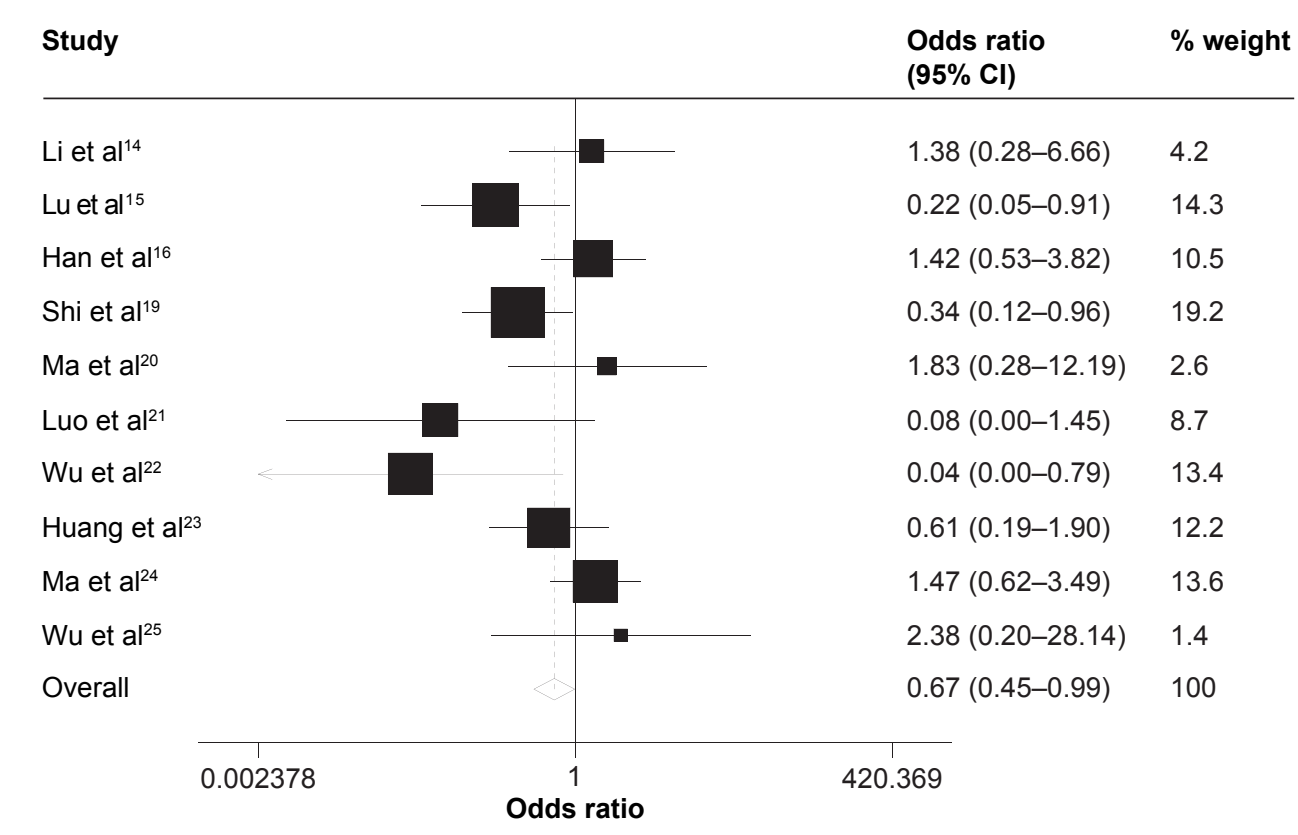

Figure 4 Forest plot of the rate of grade 3-4 vomiting.

Abbreviation: $\mathrm{Cl}$, confidence interval.

A few studies have focused on the taxane-containing IC regimen in combination with CCRT for NPC. In 2009, Hui et $a l^{30}$ reported a Phase II trial of 60 patients with NPC (stage III-IVB), who were randomly assigned to receive CCRT alone or IC (docetaxel and cisplatin) subsequently in combination with CCRT, and observed a significantly improved 3-year OS for the latter with a manageable toxicity profile compared with CCRT alone. Bossi et al ${ }^{13}$ reported a single-center study evaluating clinical efficacy and safety of IC regimen (docetaxel, cisplatin, and 5-fluorouracil) in combination with CCRT for Epstein-Barr virus-related locally advanced NPC, and revealed tolerated toxicity of the IC regimen of interest. These studies suggested that docetaxel is the major cancer drug in the taxane-containing IC regimens for advanced NPC, which is more efficient and well tolerated in patient care, consistent with the findings of our meta-analysis.

Some argument concerns that different IC and CCRT regimens and drugs utilized in each research might influence the comparison of the functions of taxane. In our meta-analysis, the conclusion of each independent research is obtained when expelling other factors which can interfere with the observation. Each independent research is focused on addressing the magnitude of the benefit and safety of taxane-containing regimen in advanced NPC treatment in Chinese population, which has been expelling other influencing factors.

In addition, of the hematologically adverse events, the incidence of grade 3-4 leukopenia and neutropenia was remarkably different between the two groups in favor of non-taxane-containing regimen, which is consistent with previous studies. ${ }^{32,33}$ But it was reported that neutropenia caused by taxane combined with cisplatin IC regimen would rebound quickly after using granulocyte colony-stimulating factor processing, while neutropenia caused by cisplatin combined with fluorouracil regimen recovered slower, leading to extended or interrupted treatment, although the rate of hematological toxicities was lower. ${ }^{34} \mathrm{~A}$ number of clinical research studies have demonstrated that much higher proportion of NPC patients could complete all the chemotherapy, ${ }^{15}$ or much more courses of chemotherapy could be completed ${ }^{18,21,22}$ when patients received taxane-containing IC regimens than non-taxane-containing IC regimens, indicating that a higher completion rate of the taxane-containing IC regimens may be due to good tolerance.

Our meta-analysis indicated that the taxane-containing regimen has a significantly improved ORR for nasopharyngeal lesion but that its other short-term efficacy and survival profiles are similar to those of non-taxane-containing IC regimens. This is mainly because of the limitations to this meta-analysis. First of all, these RCTs included different taxane-containing IC regimens using two types of different taxanes: docetaxel or paclitaxel. However, the benefits and side effects of taxane-containing regimen do not seem to vary by the taxane. Second, two different types of CCRT regimens are used during radiation in these trials: taxane and cisplatin. Third, since the IC is used for a short period 
of time in NPC, the included trials have a short follow-up with no data on the relapse. Thus, we could only compare the short-term efficacy and 1-year survival profile between the two groups for NPC treatment. Last but most importantly, all NPC patients included in this meta-analysis are Chinese people, and the sample size is not large enough. The conclusions we have made cannot be extrapolated to NPC patients of other ethnic backgrounds.

\section{Conclusion}

Limited RCTs have showed that taxane belongs to a class of clinically efficient antitumor drugs for locally advanced $\mathrm{NPC}$, and that the taxane-containing IC regimen is superior to the non-taxane-containing regimen as assessed by a higher ORR in the former for primary nasopharyngeal lesions. In the future, more multicenter, large-scaled, high-quality RCTs are required to replicate and even confirm these findings in Chinese or other ethnic populations.

\section{Acknowledgments}

The authors thank Professor Hong-Guang Xie, General Clinical Research Center, Nanjing First Hospital, Nanjing Medical University, People's Republic of China, for his critical reading of the manuscript and language editing.

\section{Disclosure}

The authors report no conflicts of interest in this work.

\section{References}

1. Wei WI, Sham JS. Nasopharyngeal carcinoma. Lancet. 2005;365(9476): 2041-2054.

2. Chan AT, Teo PM, Johnson PJ. Nasopharyngeal carcinoma. Ann Oncol. 2002;13(7):1007-1015.

3. Dickson RI, Flores AD. Nasopharyngeal carcinoma: an evaluation of 134 patients treated between 1971-1980. Laryngoscope. 1985;95(3): 276-283.

4. Buell P. The effect of migration on the risk of nasopharyngeal cancer among Chinese. Cancer Res. 1974;34(5):1189-1191.

5. Chan AT, Leung SF, Ngan RK, et al. Overall survival after concurrent cisplatin-radiotherapy compared with radiotherapy alone in locoregionally advanced nasopharyngeal carcinoma. J Natl Cancer Inst. 2005;97(7): 536-539.

6. Wee J, Tan EH, Tai BC, et al. Randomized trial of radiotherapy versus concurrent chemoradiotherapy followed by adjuvant chemotherapy in patients with American Joint Committee on cancer/International Union against cancer stage III and IV nasopharyngeal cancer of the endemic variety. J Clin Oncol. 2005;23(27):6730-6738.

7. Chan AT, Hui EP, Leung SF. Nasopharyngeal cancer: ESMO clinical recommendations for diagnosis, treatment and follow-up. Ann Oncol. 2007;18(suppl 2):ii67-ii68.

8. Chua DT, Sham JS, Wei WI, Ho WK, Au GK. The predictive value of the 1997 American Joint Committee on cancer stage classification in determining failure patterns in nasopharyngeal carcinoma. Cancer. 2001; 92(11):2845-2855.

9. Chua DT, Sham JS, Wei WI, Ho WK, Au G, Choy D. Control of regional metastasis after induction chemotherapy and radiotherapy for nasopharyngeal carcinoma. Head Neck. 2002;24(4):350-360.
10. Al-Sarraf M, LeBlanc M, Giri PG, et al. Chemoradiotherapy versus radiotherapy in patients with advanced nasopharyngeal cancer: phase III randomized Intergroup study 0099. J Clin Oncol. 1998; 16(4):1310-1317.

11. National Comprehensive Cancer Network. NCCN Guidelines ${ }^{\circledR}$. Available from: http://www.nccn.org/professionals/physician_gls/f_ guidelines.asp. Accessed July 9, 2015.

12. Nabell L, Spencer S. Docetaxel with concurrent radiotherapy in head and neck cancer. Semin Oncol. 2003;30(6 suppl 18):89-93.

13. Blanchard P, Bourhis J, Lacas B, et al; Meta-Analysis of Chemotherapy in Head and Neck Cancer, Induction Project, Collaborative Group. Taxane-cisplatin-fluorouracil as induction chemotherapy in locally advanced head and neck cancers: an individual patient data metaanalysis of the meta-analysis of chemotherapy in head and neck cancer group. J Clin Oncol. 2013;31(23):2854-2860.

14. Li XP, Bai GP, Wei N, et al. The short-term effect of TPF, PF induction chemotherapy followed by chemoradiotherapy for local advanced nasopharyngeal carcinoma. J Mod Oncol. 2012;20:2031-2033.

15. Lu X, Guo X, Hong MH, Chen QY, Zeng Q, Xiang YQ. Comparison of the short-term efficacy of two inductive chemotherapy regimens for locally advanced nasopharyngeal caricinoma: docetaxal plus carboplatin versus 5-fluorouracil plus carboplatin. Chin J Cancer. 2010;29: 140-144.

16. Han SH, Yu L, Zhang Z, Zhang PJ, Song HP, Guo CY. Evaluation of induction chemotherapy with vinorelbine plus cisplatin (NP) or docetaxel plus cisplatin (TP) combined with concurrent chemoradiotherapy for patients with locally advanced nasopharyngeal carcinoma. Zhonghua Zhong Liu Za Zhi. 2013;35(8):623-626.

17. Liu GC, Hu XF, Huang GS, et al. A clinical research on the TPF or PF neo-adjuvant chemotherapy combined with concurrent chemoradiotherapy in the treatment of locally advanced nasopharyngeal carcinoma. Anti-Tumor Pharm. 2013;3:204-212.

18. Xie FY, Qi SN, Hu WH, Zou GR, Peng M, Li JS. Comparison of efficacy of docetaxel combined cisplatin (TP regimen) and cisplatin combined 5-fluorouracil (PF regimen) on locally advanced nasopharyngeal carcinoma. Ai Zheng. 2007;26(8):880-884.

19. Shi MH, Cheng JF, Wang L, et al. Comparison of efficacy of induction chemotherapy between docetaxel combined cisplatin (TP) and cisplatin combined 5-fluorouracil (TP) for locally advanced nasopharyngeal carcinoma. Modern Oncology. 2014;22:537-539.

20. Ma JJ, Zhang YB, Zhao MH, et al. Short-term treatment effect comparison of TPF, PF induction chemotherapy followed by chemoradiotherapy for local advanced nasopharyngeal carcinoma. Anhui Med Pharm J. 2011;15:1291-1293.

21. Luo JH, Lin Y, Zhou J, et al. Clinical study of inductive chemotherapy with docetaxel plus nedaplatin followed by concurrent nedaplatin with radiotherapy for advanced nasopharyngeal carcinoma. Tumorsci. 2011; 31:523-537.

22. Wu F, Wang RS, Wei B, Zhang Y, Liu WQ. Clinical efficacy of inductive chemotherapy with docetaxel plus nedaplatin followed by concurrent nedaplatin with radiotherapy for locally advanced nasopharyngeal carcinoma. Herald Med. 2013;32:459-463.

23. Huang SN, Wang RS, Liang FF, Du QH. Inductive chemotherapy followed by chemoradiotherapy for locally advanced nasopharyngeal carcinoma. Chin J Cancer Prev Treat. 2013;20:614-617.

24. Ma HM, Yuan X, Huang YL, Lin YF, Liu CX. Paclitaxel and cisplatin, 5-fluorouracil (TPF) programme neoadjuvant chemotherapy for advanced nasopharyngeal cancer. Mod Oncol. 2009;17:1233-1235.

25. Wu JT, Peng JY, Wu CB, Ding JT. The efficacy of induction chemotherapy with TPF scheme for locally advanced nasopharyngeal carcinoma. Pract J Cancer. 2014;29:143-145.

26. Cochran WG. The comparison of percentages in matched samples. Biometrika. 1950;37(3-4):256-266.

27. Higgins JP, Thompson SG, Deeks JJ, Altman DG. Measuring inconsistency in meta-analyses. BMJ. 2003;327(7414):557-560.

28. Mantel N, Haenszel W. Statistical aspects of the analysis of data from retrospective studies of disease. J Natl Cancer Inst. 1959;22(4): 719-748. 
29. DerSimonian R, Laird N. Meta-analysis in clinical trials. Control Clin Trials. 1986;7(3):177-188.

30. Hui EP, Ma BB, Leung SF, et al. Randomized phase II trial of concurrent cisplatin-radiotherapy with or without neoadjuvant docetaxel and cisplatin in advanced nasopharyngeal carcinoma. J Clin Oncol. 2009;27(2):242-249.

31. Bossi P, Orlandi E, Bergamini C, et al. Docetaxel, cisplatin and 5-fluorouracil-based induction chemotherapy followed by intensity-modulated radiotherapy concurrent with cisplatin in locally advanced EBV-related nasopharyngeal cancer. Ann Oncol. 2011;22(11): 2495-2500.
32. Tsukuda M, Mikami Y, Tanigaki Y, et al. Phase I trial of combined chemotherapy with docetaxel, cisplatin, and 5-fluorouracil for patients with locally advanced squamous cell carcinoma of the head and neck. Int J Clin Oncol. 2004;9(3):161-166.

33. Genet D, Cupissol D, Calais G, et al. Docetaxel plus 5-fluorouracil in locally recurrent and/or metastatic squamous cell carcinoma of the head and neck: a phase II multicenter study. Am J Clin Oncol. 2004; 27(5):472-476.

34. Kwong DL, Sham JS, Au GK, et al. Concurrent and adjuvant chemotherapy for nasopharyngeal carcinoma: a factorial study. J Clin Oncol. 2004;22(13):2643-2653.

\section{Publish your work in this journal}

OncoTargets and Therapy is an international, peer-reviewed, open access journal focusing on the pathological basis of all cancers, potential targets for therapy and treatment protocols employed to improve the management of cancer patients. The journal also focuses on the impact of management programs and new therapeutic agents and protocols on

\section{Dovepress}

patient perspectives such as quality of life, adherence and satisfaction. The manuscript management system is completely online and includes a very quick and fair peer-review system, which is all easy to use. Visit http://www.dovepress.com/testimonials.php to read real quotes from published authors.

\footnotetext{
Submit your manuscript here: http://www.dovepress.com/oncotargets-and-therapy-journal
} 